\title{
6. Situated Installations for Urban Data Visualization: Interfacing the Archive- City
}

\author{
Nanna Verhoeff and Karin van Es
}

\begin{abstract}
We propose a set of analytical concepts that help analyse how media/ interfaces situate us within our cities and in connection with the invisible digital data that surround us. We recognize a set of architectural, cartographic and archaeological principles that structure the way the interfaces allow us to navigate the city as an emergent and layered data archive. These concepts help us investigate how interfaces not only communicate data as information, but, more importantly, structure, if not control, our agency within the visual regime that they sustain. Moreover, they help to understand and articulate how creative and critical artistic practices in the spaces of our cities contribute to public debates about the significance of digital data in contemporary society.
\end{abstract}

Keywords: data; visualization; archive; urban interfaces; installation; performative archaeology

The world is becoming increasingly 'datafied' as all aspects of life previously unquantified are now being translated into digital data (Van Es \& Schäfer, 2017; Cukier and Schönberger, 2013). So-called Big Data have the capacity to reveal information about the past and to inform the future. The open data movement argues that data is a public good and seeks to democratize the production of information and knowledge. The access and reusability of public information, it is argued, allows for the public scrutiny of institutions and stimulates informed and active citizen participation. The challenge facing this movement is that data must not only be made accessible, but also

Dibazar, P. and J.A. Naeff, Visualizing the Street:New Practices of Documenting, Navigating and Imagining the City, Amsterdam University Press, 2018 DOI 10.5117/9789462984356_CHO6 
understandable. Data visualizations are commonly used to make sense of data and to communicate that sense (Kitchin, 2014: 106). Urban dashboards, for instance, 'render a city's infrastructures visible and make tangible, or in some way comprehensible, various hard-to-grasp aspects of urban qualityof-life' (Mattern, 2015). Art projects, on the other hand, experiment even more explicitly and reflexively, sometimes critically, with the possibilities for visualizing and layering data within (and 'onto') the physical environment from which it emanates, with the aim to create awareness and activate citizen participation around urban challenges (Brynskov, Galsgaard and Halskov, 2015; Vande Moere and Hill, 2012; Wiethoff and Hussmann, eds., 2017).

In the following we will take up their suggestion to reflect on, precisely, the questions these experimentations raise: How do these situated, sometimes architectural, media installations provide us with interfaces for exploring pervasive and emerging urban data? We depart from a perspective on the city as an ever-expanding source of all sorts of data, to address the fact that they are simultaneously historically situated and emergent. Herein we investigate the principles of making visible this urban archive on location and in real time. These principles are made manifest by exploring the data visualization experiment Deep City, an example of a project that explicitly works with the affordances as well as the limitations of networked and geo-locative technologies and the (cultural) interfaces that we use to connect to, reconstruct, or perform the urban archive.

Rather than an aesthetic analysis or review of the criticality or effectiveness of the project, our aim is to propose an analytical approach to the spatiotemporal design of the work as an interface that structures these data with local, urban publics. This approach, as we will expand on below, is useful for a comparative perspective on situated installations, urban screens or media architecture. In other words, we use this project not only as an object to think about, but also an object to think with (Verhoeff and Wilmott, 2016). ${ }^{1}$ We explore the way the historical layering of urban space can be considered as being activated, if not visualized in the sense of 'made visible' by the principle of navigation - whether or not by means of location-based interfaces. This perspective of the city as a spatially distributed and historically layered archive pushes out the more conventional idea of an archive as a spatially demarcated, heterotopic repository of the past, and re-evaluates it as situated,

1 Our idea of an object to 'think with' is meant in a slightly different way than in Sherry Turkle's proposal (2007). Rather than focusing on the relationship between material objects as provoking thoughts and affects, we have an analytical aim. Here, the installation as 'object' is a situated practice that raises theoretical questions about its operation rather than its thingness. 
present and future-oriented. In other words, we argue that these interfaces are simultaneously architectural, cartographic and archaeological in how they, respectively, design and structure space, organize mobility and make accessible the city as a navigable, location-based and emergent archive by establishing dynamic relations between subject, time and place.

\section{The City as Layered Data Archive}

Thinking of the modern city as a navigable archive has a history. Walter Benjamin's flâneur walked the streets without a fixed, geographical destination; a navigation without end point, but with a purpose: to understand the metropolis on its own terms, collecting both from and towards an ongoing (forever 'unfinished') urban archive. Usually this is understood in terms of pastness and memory. Mike Featherstone (2006) invokes the fragmented and inherently fugitive nature of Benjamin's city as archive:

For Benjamin the city was an archive, an archive already in ruins, in which the minutiae of everyday life (the decorations on buildings, ironwork, street signs, advertising bills, posters, window displays, etc.) all have the capacity to speak. Yet these fragments could only speak the language of broken, incomplete allegories, summoning up half-formed memories which appeared vividly as in a lightening flash and then were gone. (594-595, our emphasis)

Todd Presner, David Shepard and Yoh Kawano (2014) call the Benjaminian flâneur a 'time traveller' (23). In their words, in the city's streets:

[...] the past is always there - quiet, muted, faded, hidden - and it is the task of the flâneur to enable it to speak, to make it come alive and come to light, and thereby resonate with the present. In this sense, the past must be conjured, awakened, and cared for. (Presner, Shepard and Kawano, 2014: 23)

This figure, or rather, the navigator as conjurer of the past, 'summoning up' memories (as Featherstone phrases it) is, however, not only of 'other' times, but emphatically takes place in the present and points towards a future. As navigable and layered, this archive-city is ever-expanding - both geographically and historically - in a synchronic and diachronic layering. Presner, Shepard and Kawano (2014) speak about HyperCities and what they call 'thick mapping', as a model to think about cities' multitude of expanding and changing (rhizomatic) configurations of past, present and future. 
Vyjayanthi Rao (2009), inspired by Georg Simmel's seminal writing on the city in 'The Metropolis and Modern Life' (1903), also tackles this implication of approaching the contemporary city as an ever-expanding archive. From Simmel's understanding of the metropolis as medium, Rao points out how the archive is emergent and orders 'stimuli upon which future transactions are imagined and made present rather than a given notion of the past that has been deemed significant and marked for preservation' (Rao, 2009: 374). This is particularly relevant in the case of current urban culture with the ubiquitous presence of ephemeral, invisible and continuous flows of all sorts of (digital) data. As we aim to unpack in this essay, this connectivity between the present and past - conjured up and curated, or 'cared for' - is very much where the futurity of (urban) navigation lies (Verhoeff, 2012).

Indeed, through projects of locative data visualization such as Deep City, we are reminded of the emergent and situated character of data itself, as produced by our activities in the world. As boyd and Crawford state, this entails 'massive quantities of information produced by and about people, things, and their interactions' (2012: 663). This is where the project of data visualization meets the performative potential of locative, interactive media: making urban, public data public in public spaces. In the media city (McQuire, 2008) we produce data continuously, captured and stored in expanding data sets. A spatial archive, the city is perhaps best conceived of as an emergent data repository, permanently in flux.

To investigate how this relationship between past and future works in the streets of the city, we are interested in the way media installations as situated (urban) interfaces for visualizing urban data are designed to bring the multiple layers in connection, to make them navigable. Indeed, when we think of the archive as a continuous effort to collect, order and preserve with the goal of making (future) access and visibility possible, we are reminded that the archive is very much of and about the present, as well as about presence - a presence that is fugitive by definition, which brings in its wake both a historicity and a futurity. A perspective of the city as archive suggests that the city is both a navigable and fundamentally layered space. Moreover, it suggests that our 'being in the city' is constitutive of an (ongoing) act of presencing - of ourselves within and in relation to these layers. ${ }^{2}$ In this process of interfacing between ourselves, our urban surroundings and with data layered locations, we recognize architectural, archaeological and

2 Brendan Hookway (2014) emphasizes this presencing as the working of interfaces (8). We can consider the street as a navigable interface to the urban archive - an urban interface. 
cartographic principles. These principles, we argue, govern the way the interface design allows for urban publics to engage with the data that are made visible and, hence, present by these works.

\section{The Architectural: Deep City as Visualization Zone}

Deep City is an urban data visualization experiment presented at the Ars Electronica festival in Linz and was developed for the 2015 programme of Visible Cities by Ursula Feuersinger. The four sides of the Ars Electronica Center were used to visualize the tension among inhabitants, activities and resources in Linz, Vienna, Berlin and New York. These findings were based on the following eight statistical data sets grouped in pairs: Growth/ Diversity, Green Spaces/Bike Paths, Water Usage/Waste, and Density/Noise Exposure. ${ }^{3}$ They were gathered in a console in front of the building that visitors could navigate (see Figure 6.1) using a wheel for scrolling through data sets and a cube that allows for switching between cities.

Data art is said to be about making the invisible visible (Grugier, 2016). Indeed, Feuersinger articulates the ambition to, in her words, 'visualize' and 'bring to the surface hidden layers of data', about remote urban spaces. ${ }^{4}$ It makes visible the 'hidden' layers of the urban archive, uses a multiplicity of data sources and situates its readings in a vociferous terrain of polyvocal citations. Here, however, 'urban data' is displayed on a media architecture in the urban context. The curators of Deep City advocate a role for architectural façades and urban screens as 'black boards' and 'visualization zones' for information. ${ }^{5}$ They ask:

How can we make social, environmental and intercultural processes visible and use the screens as black boards and visualization zones? What is the impact on the society, when invisible structures that underlie our daily life get visualised? What is the potential to create public awareness? ${ }^{6}$

3 In email correspondence (June 2016), the artist explained that she tried to find the latest, most correct and comparable data for the topics and cities, which proved difficult and not always successful. However, it was always her main ambition to create playful and engaging public experiences, rather than scientifically sound visualizations.

4 For an interview with the artist, see https://ars.electronica.art/futurelab/en/project/ connecting-cities-european-network-media-facades.

5 For a discussion of urban screens as visualization zones for the city's invisible communication sphere, see Struppek (2011).

6 http://www.connectingcities.net/city-vision/visible-city-2015 


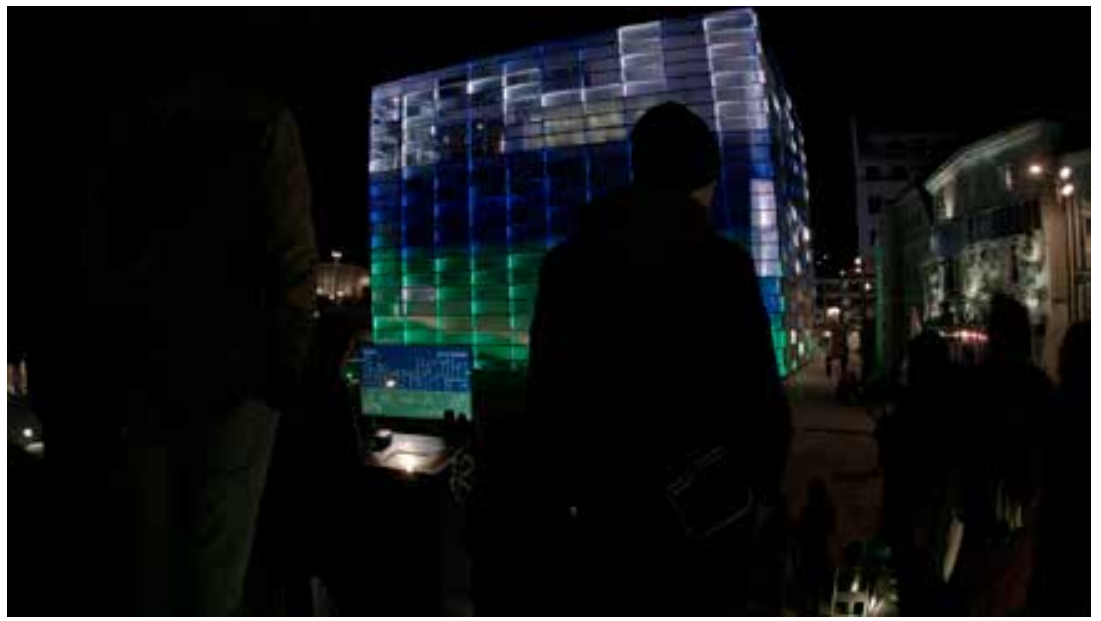

Fig. 6.1: The lit up façade mirrors the colours and image on the smaller display at the console, showing the greens spaces in Berlin. Image: Ursula Feuersinger.

Deep City is a time-based visualization of urban processes, using the façade as 'visualization zone'. As media architecture, the installation visualizes the urban archive by working with access and display. It is thought that the public visualization of situated and contextual information can create actionable understanding among citizens for urban issues (Vande Moere and Hill, 2012). The digital traces of the city, previously invisible, are made visible and even tangible on this façade, which functions as an interface to the data sets of the city. As Mitchell Whitelaw states about data art, 'It draws data out, makes it explicit, literally provides it with an image' (2008, np).

As a material structure, the installation is layered. Not only materially and spatially but also temporally, in the sense that it is both relatively permanent and radically temporary. It borrows its permanency - as far as buildings ever are permanent - from the pre-existing interactive LED façade of the Ars Electronica Center. At the same time, it is temporary because of the fact that it is one of many projects designed to change the mutable surface of this one façade. This temporality is also captured in the above quoted reference to screens and media architecture as reusable writing surfaces.

But more importantly than this architectural layering, the project is fundamentally about layering: the (invisible) layering of urban space by the data we generate by living in it. Difficult, perhaps impossible to itself be archived for its own radical temporality, this installation aims to visualize, and, as we claim, thereby to perform the archival. According to the artist, the project 'investigates the collective information that defines the city's 
present and potential future through a data visualization experiment'. ${ }^{7}$ She proposes the metaphor of archaeology for the endeavour to visualize the urban archive. To quote at length:

Just as a city's history can be uncovered by an archeological dig, the collective information that defines its present and potential future can be represented as a digital cross-section, emerging from underneath its concrete, visible structures. The Ars Electronica Center façade will put these underground samples on display: Observers of the project transform into participants by physically extracting hidden artefacts from the deep, bringing them to the surface, and examining them. The resulting layers of visualized data emphasize various political, sociological, cultural, or even personal characteristics of an urban space, encouraging the inhabitants of that space to critically engage with their surroundings. ${ }^{8}$ (our emphasis)

In these somewhat ambitious terms, the underlying premise seems to be that interactive, visual technologies enable a form of (physical) contact with data. But perhaps more pertinent to our inquiry here, these words also suggest that this form of contact is essential to the act of visualization itself.

\section{The Cartographic: Navigational Engagement with Data}

Data mapping, the process of visually representing data, is an inherently political process and involves questions about who has the power to select how to map, what dimensions to include, and through what interface to give users access (Manovich, 2002). The cartographic principle of interactive installations is inherent in the way they structure spatial relationships and navigation for the engaging subject (Verhoeff, Cooley and Zwicker, 2017). Our take on this cartographic principle of interactive installations is focused on this organization, or scripting of the subject's engagement with data, as first and foremost a matter of access to data and agency in this process.

In his writing on interfaces, Daniel Chamberlain (2011) reminds us of Norman Klein's critical reading of exhaustively planned physical environments as scripted spaces. Chamberlain adopts Klein's terminology for his analysis

7 From the announcement of Ars Electronica's Future Lab, 2015, available at http://www.aec. at/futurelab/en/project/connecting-cities-european-network-media-facades. See also http:// www.aec.at/postcity/en/deep-city/ for a video impression of the project.

8 http://connectingcities.net/project/deep-city 
of media interfaces, which establish what he calls interactive scripted spaces that provide users with predetermined parameters of access to data, to 'frame the contemporary cultural and economic implications of emergent media technologies' (2011: 239). Andersen and Pold (2011) use the term scripted space in their work too, albeit more explicitly in reference to ubiquitous computing in urban spaces:

Besides being a continuation of the ways urban space has been planned, scripted space also has a more contemporary dimension which is linked to the computer. Scripted space has a non-visual, coded, encrypted side to it and suggests that there are computed transactions and control structures behind the facade, surface, or interface of the city. (112)

The perhaps restricting cartographic principles of the interface - here, installation - in its structuring and delimiting of access and agency work towards not only a form of mapping, but thereby also a scripting of the terrain of navigation.

We can recognize a scripting at work in the installation of Deep City in how the interface distributes agency in the urban archive. The artist as curator has compiled and organized the data to be used as input for the visualization, selecting from attributes of the city that have been captured in data sets. She furthermore paired data sets with the intent of contrasting their elements. Unlike projects that use (or approximate) real-time data streaming, in this case the data sets are fixed, stored 'in' the apparatus. The material and spatial arrangement comprises a separate-but-connected terminal or console, by means of which the participants can browse and select data sets and can have some input in what is shown on the façade. The console incorporates two interaction elements for participants: a wheel that facilitates browsing through colour-coded topological layers and a $3^{\mathrm{D}}$-printed cube to switch between the content of different cities. They can 'engage' by playful, exploratory browsing, combining and comparing data sets from different cities and thereby composing a colourful show of lights on the building's façade.

As such, it invites local urbanites as passing and distant observers to become more attentive to their surroundings - and for those within reach of the installation's console to even become active engagers. Here, we encounter the urban archaeologists on their dig. Strictly speaking, browsing the data through a crank does not make the interactors co-creators of the visualization. At most, they can select input for the algorithms that select and process the social and personal data 'below the surface' (as Feuersinger phrased it) 
to translate these data sets as input for the project's 'visualization zone' at the surface. The console operates as a black box concealing the processes in between input and output for participants. Moreover, not all city dwellers can take part in the action - take a place, literally, 'behind the wheel' or 'at the console' to produce the view. For most, it remains a distant spectacle.

However, the installation does suggest you can, in principle, become a co-performer of the act of visualization. Even if just playful, temporary or literally 'eventful', the project taps into current debates about what Rob Kitchin (2014) has called the 'data revolution': the changing landscape of ownership of, and shared access to data, new forms of participatory engagement and smart technologies becoming more and more embedded in the materials, design and infrastructures of our cities. Indeed, the rhetoric of big data, individual agency and civic participation in the self-presentation by the artist emphasizes how this project is a sign, or a Foucauldian monument, of its time.

\section{The Archaeological: Visualization as Installation}

Feuersinger discloses that one of the main points on her agenda with Deep City is to make people aware of their direct connection to the city and the data through this installation. ${ }^{9}$ She reflects on the affective dimension of the installation and how the data is made no longer to be just 'cold, impersonal numbers'. Its goal as such is what Kim and DiSalvo (2010) would call artistic rather than pragmatic, raising awareness of the city as a data archive, rather than providing access to its information. Where Lev Manovich (2002) critically asks how data visualization art can aim 'to represent the personal subjective experience of a person living in a data society' (np), we find that Deep City suggests that visualization is less about representation, than it is about performativity.

In the very act of making visible, data becomes a spectacle. Indeed, the question is: Can the observer actually read this spectacle she conjures by flipping a switch or turning a wheel? In addressing this question, it becomes relevant to recall the important, but often overlooked, distinction between data and information. The former is the meaning derived from the latter in a given context (Whitelaw, 2008, np). The spectator at the console can browse the data to perform data-as-information. What is put on display may be visible, but does not facilitate 'actionable information' (Weinberger, 2011). 
However, it potentially triggers an affective response and arouses curiosity, or awareness of the big data that, while usually invisible, pervades the city. More fundamentally, this façade as screen demonstrates the differences and tensions between 'input' and 'output'; and between 'observation' and 'knowledge'.

The fact that this project invites individual playful interactions, but as 'visualization zone' for data also becomes a fugitive, distant spectacle, raises some questions that are specifically relevant for the investigation of these works as urban interfaces. Access in the form of a visual display, in this installation, both reveals and problematizes the possibilities for, and limitations of shared and open access to big data for exploration, examination and analysis. The impact of visualization, its potential both to create awareness and (subsequently) meet the ideals of civic participation is not straightforward. Indeed, upon closer inspection, we can see how, as an experimental project, Deep City affirms and questions the impact of visibility. Its most urgent questions, as we have seen above, are directed at agency, comprehensibility and actionability.

Perhaps Deep City does not so much provide access to (in the words of the artist) the 'layers of visualized data' that are 'hidden' in cities, but more importantly demonstrates the sheer fact that these can be made visible and that it can connect them to - make them navigable for - the city dwellers. In other words, it visualizes (the act of) visualization. As such, it does what it says - which is the classical definition of performativity as J.L. Austin proposes in his seminal work How to Do Things with Words (1975), or, as we can add: with other kinds of signs. Following that logic, however, it also implies that the work does not do what the artist proposed when we equate access to actionability. ${ }^{10}$ It exposes the fact of data rather than the meaning of data.

\section{Triangulating City, Data, and Subject}

These architectural, cartographic and archaeological principles - all three in an emphatically performative gesture - not only make visible, but also put 'into place' the digital data that surrounds us and set the parameters for the urban spectator to engage with these data. As such, installations as interfaces to urban data, not only visualize, but also situate both these data and the urban subject. We propose to look at how we may utilize

10 This actionability is how citizens are made to feel a sense of responsibility towards place, encouraging 'place-making' (Vande Moere and Hill, 2012: 27). 
this perspective for distinguishing different relationships between data, subject, and city as constructed by other artistic and creative projects of data visualization that aim to raise awareness around local, urban issues. These projects all put forward, albeit in different ways, the triangulation at the heart of this relationship between data, subject and city. They help to probe how interfacing is a useful concept for thinking about how this type of installation works. The varieties in this triangulation produced by these different interfaces - or, better, acts of interfacing - demonstrate not only the city as archive, but, perhaps more importantly, how we are positioned and navigate within our complex and layered environment. ${ }^{11}$

Deep City is a good example of what Vande Moere and Hill (2012) refer to as physical and situated visualizations. It demonstrates how data made visible within the environment directly reflects the environment. Vande Moere and Hill contrast physical and situated visualizations to projects where screens, websites or smartphone apps are used to interface with data sets in a virtual elsewhere (2012: 29). For us, the interest lies not in the potential persuasive power of this relationship, as is their primary concern, but rather in the questions raised by these configurations about access to the layers of data that constitute the urban archive.

To follow up on our suggestion for a comparative approach to the broader category of situated urban installations, we want to bring in additional projects and reflect on how they interface the archive-city. In addition to the way Deep City projects and visualizes, we identify two complementary, yet very different, interfaces that nonetheless also demonstrate the (latent) architectural, cartographic and archaeological principles of interfacing: wayshowing and sensing. ${ }^{12}$ In other words, this comparative approach highlights not only the acts of interfacing, but also what is produced in the process. Both these interfaces facilitate and structure the relation between data, subject and city in a distinct way and brings forward the translations that occur between the 'lived' and 'abstracted' archive, making the city sensible to the subject. ${ }^{13}$

11 This potential messiness of the 'sea of data' makes us navigators - an aim of data visualization to make sense of the abundance and potential illegibility of data is precisely to makes sense and 'clear paths', and perhaps even protect, or, as Shannon Mattern (2015) has pointed out in the case of urban dashboards, the history of keeping out the 'dirt' (np).

12 These have been oversimplified and are by no means exhaustive, but reflect general tendencies to organize relations between data, subject and city.

13 We here draw on the definition of the interface by Steven Johnson: 'the interface serves as a kind of translator, mediating between the two parties, making one sensible to the other' (1997: 14). 


\section{Wayshowing}

The White Spots App (2016), developed by Richard Vijgen in collaboration with Bregtje van der Haak and Jacqueline Hassink offers a critique of connectivity by visualizing the pervasive presence of radio waves emanating from GSM cell towers, based on open data from the OpenCellID database. More specifically, the app transforms the mobile phone screen into a network scanner, visualizing the presence of invisible digital devices in our direct surroundings and in real time. By pressing the 'get me out!' button featured beneath the visualization, users are brought to the map mode. Here, the connected and disconnected world is portrayed. Users are invited to watch documentary shorts pinned on locations in the map, or to navigate to places off the grid, so-called 'white spots', by activating the GPS route planner mode. The installation thus acts as a wayshowing interface (Mollerup, 2013), making the otherwise inconspicuous pedestrian pathway not only more visible, but also more engaging. ${ }^{14}$

Different from Deep City and related installations, this mobile app works on a mobile micro screen, perhaps a navigational - here, wayshowing interface par excellence. The navigational logic of this app is paradoxical in two ways. First, it makes visible (and audible!) the invisible, so that the user is confronted with the overwhelming wireless signals that populate our surroundings, and helps the user to navigate to a disconnected area. Secondly, as a strategy of sousveillance (Mann, Nolan and Wellman, 2003:333) - flying under the radar of surveillance technologies with the result of reflecting (on) these technologies - it precisely visualizes and, hence, tackles the problem of data and the logic of pervasive signals and surveillance technologies, and how they encroach upon us and attack our sense of autonomy, privacy and even physical well-being. This particular form of interfacing - emphasized by the on-screen greeting 'Hi Explorer!' - addresses the subject as a knowledgeable and tech-savvy urban explorer daring to venture off-grid. Moreover, it not only shows the way to elsewhere, but, in its visualization, it primarily points to the subject's presence within her surroundings.

\section{Sense-ing}

In the Air, Tonight (2014) is a project that makes use of an LED façade of the Ryerson Image Centre in Toronto. Similar to Deep City, this is an installation 


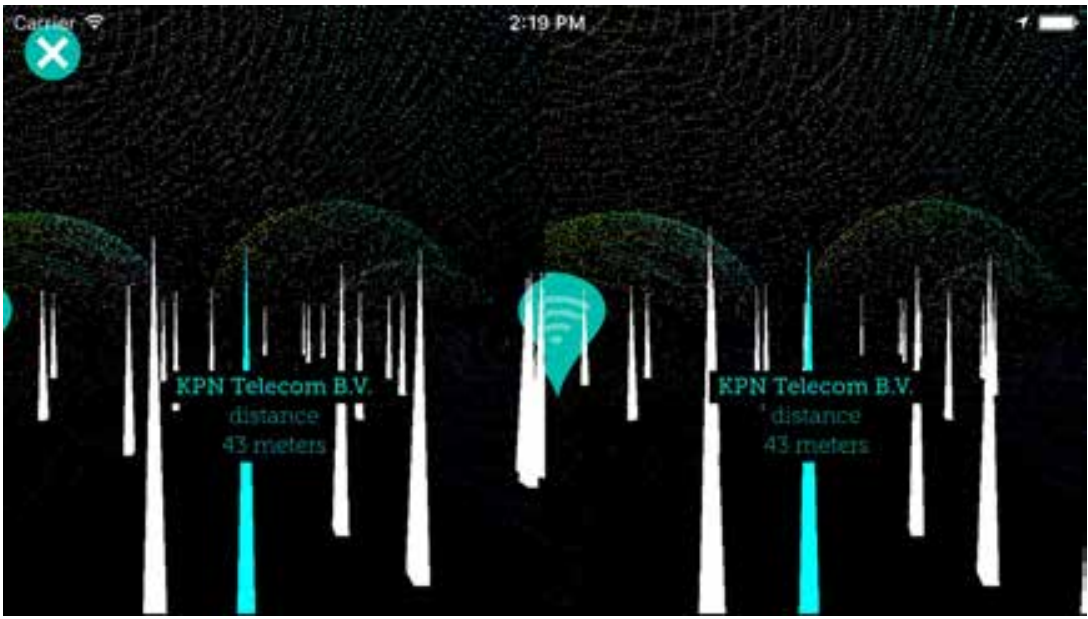

Fig. 6.2: White Spots used as network scanner, showing the presence of electromagnetic clouds. Image: Richard Vijgen.

for an existing and fixed architecture, that is temporary: it is put up for a month, with the aim to raise awareness about homelessness in the city. In the visualization zone, throughout February evenings, a blue wave fluctuates, sensing changing temperatures and wind speed. This visualizes the 'feeling' of being outside and exposed to the elements, translating the one sense (touch) to the other (sight). The data 'in between' - from qualitative to quantitative and back - comes from a weather station located on the roof of the building. Tweets using the hashtag \#homelessness generate a red pulse on the surface and donations cause the façade to turn white. A webcam allows participants to see the building change colours in real time remotely.

Interesting in this case is how the design of this installation translates a social issue ('homelessness') to a physical and experiential category ('feeling cold') to something we can measure ('temperature') and subsequently evaluate and relay in a (metaphoric) visual form (blue wave signifying 'coldness'). Moreover, as a composite installation, it combines different data sources (temperature, number of tweets) that are drawn from different locations and materialities, symbolizing different indexical relationships. By combining outside temperature and online tweets, the installation makes a connection between very different spaces, situating and making visual - hence, material - and sense-able digital communication. This particular form of interfacing is transformative in its attempt to make perceptible urban challenges often taken for granted and, as such, produces awareness, reflexivity and a feeling of being compelled to act. A subject is positioned as an insightful and conscientious citizen, aware of the presence 


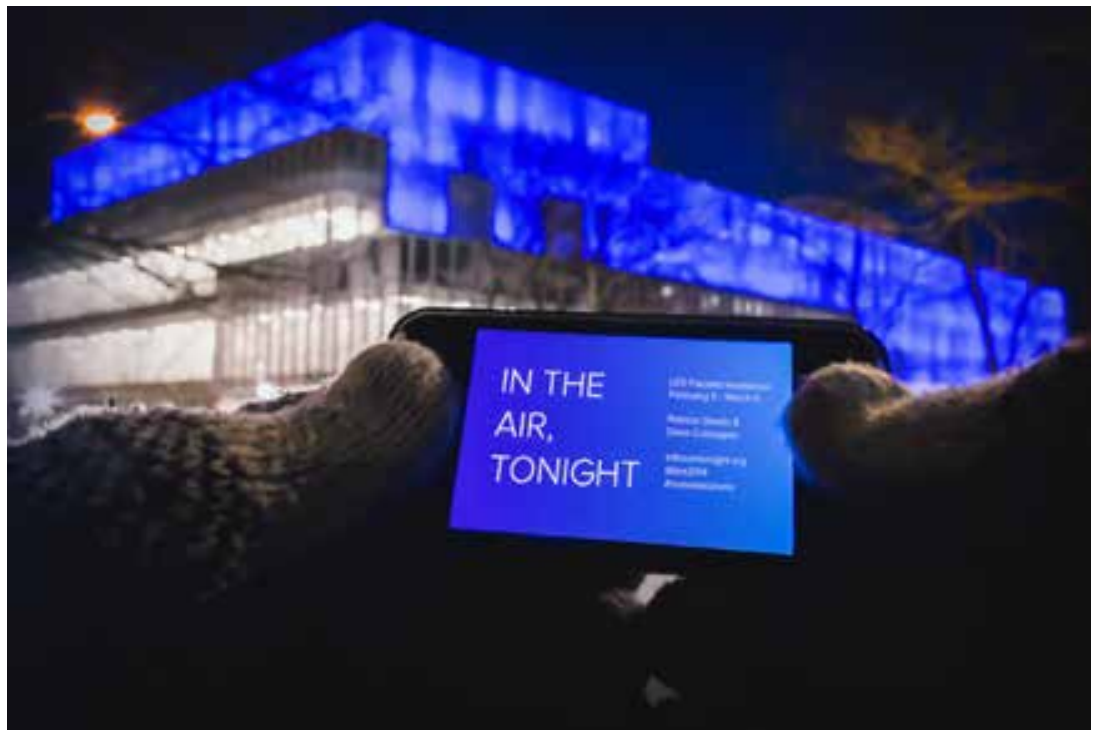

Fig. 6.3: Façade connecting to micro screen in the installation In the Air Tonight. Image: Public Visualization Studio.

and situation of others, and stimulated to make donations as contribution to an improvement to this situation. ${ }^{15}$

The relationship that is established between data, city and public in Deep City as well as these two additional cases just explored, all hinge upon the triangulation at the heart of the architectural, cartographic and archaeological principles of interfacing. Albeit in various ways and to different degrees, these projects all demonstrate how data visualization enacts forms of interfacing that, aside from communicating data from and about 'here' and 'there', are also about the 'now' of the subject in relation to this data. It is within this relationship and in the process of interfacing that data is extracted, sensed, translated, connected, made present, made visible and, perhaps more pertinently, performed - a process which also implicates the subject.

\section{Conclusion: Towards a Performative Archaeology}

The designer of Deep City presents her project as an archaeological endeavour to access and visualize the archive-city. Her statement bristles with 
words that suggest this: 'an archaeological dig', 'uncovering', 'extracting', 'underneath', 'from the deep', 'bringing them to the surface, and examining them'. Here, the archaeological metaphor that brings in the time-space dynamic meets the architectural - the spatial and material design of the building as blackboard for the installation - and the cartographic in the way it proposes a mapping of the city's spatiotemporal layering. In this collaboration between the architectural and the cartographic, Deep City visualizes the city as a living archive of today, its excavations live, in and about the present. This infuses archaeology with the contemporary - thus studying the coexistence of past and present. The spatial metaphor, the comparant of 'depth', here is not, as is usual, equal to the temporal comparé of 'long ago', but shifts to a new comparé, namely 'visibility'. What 'depth' suggests invisibility, while what is brought to the surface becomes visible. Performative archaeology visualizes this act.

We gratefully take the artist's metaphor, but wish to make explicit how this small-seeming shift in fact signals a change of paradigm. Under the same comparant, the older idea of a layered past is pushed out and the discourse smuggles in a new comparé, which is spatial, situated in the present and brought in connection with the future. It is, in other words, that which is embedded in what 'emerges'. To understand this, we need to recall an argument made elsewhere concerning navigation as performative cartography. Navigation, as an act of making visible, is a future-oriented self-affirmation in the present (Verhoeff, 2012). Thus, it construes a subject that is engaged with her surroundings in transition. Importantly, in view of the shift in the archaeological metaphor's comparé, this means that the movement (the 'digging') goes from the evolving present towards the future destination. The digital traces of the city's past are connected to the present, they inform and intensify the present. The Connecting Cities website reflects on the installation in a similar manner, in that it is said to be about 'investigating the collective information that defines a city's present and future' (our emphasis). ${ }^{16}$ However, in the understanding of the city as defined by this 'collective information', as Donna Haraway (1988) has reminded us, knowledge production is indeed always situated and partial. Indeed, we are not commenting on the epistemological value, but rather on the discursive gesture and affective quality of contemporary urban visualizations as performative archaeology.

If we consider the city an archive, our activities within it actively contribute to the expansion of this archive in the continuity from present to 
past. Moreover, since the present never remains, is always 'on the move', this archiving of the present is always already just one step away from the future. Therefore, navigation allows us to think of the archive as constituted within an emergent, future-oriented present. It is thus (a) live, rather than a storage site of everything past. The navigation of the archive is constitutive of the subject in relation to the world around her in an ongoing act of relative positioning in time, as the terrain between past and present shifts.

The paradigm shift to performative archaeology implies a thinking of the present as the moment the archive is activated when it becomes visible (and potentially legible), but also as fundamentally unstable because it is emergent and inherently future-oriented. If the archive-city is constituted, seen and read in the present, the present is also the moment of the archive's ongoing transformation. Perhaps we should stop considering the archaeological metaphor as a metaphor, so it can become more humbly yet more clearly the handmaiden of, or teacher for, our understanding (and analysis) of time and space together and layered within different configurations. Whereas the architectural principle of interfacing refers to materiality, structure and surfaces, and the cartographic to the spatial relations it affords, it is the archaeological principle of interfacing that fuels temporal relations produced and performed in visualization.

When we look back at Deep City as a reflection on the city and White Spots and In the Air Tonight as reflections on our experiences and sensations in this city, in the end, the liveness of the installation confirms not only the present - both as moment and as tense - but, most importantly, in its constitutive gesture it confirms presence: our connected and moving being in the here and now in the streets of our cities.

\section{Bibliography}

Andersen, Christian Ulrik, and Søren Pold (2011) 'The Scripted Spaces of Urban Ubiquitous Computing: The Experience, Poetics, and Politics of Public Scripted Space,' The Fibreculture Journal 19:110-125.

Austin, John Langshow (1975) How to Do Things with Words. The William James Lectures delivered at Harvard University in 1955, ed. J.O. Urmson. Second Edition. Cambridge, MA: Harvard University Press.

Bench, Harmony (2017) 'Dancing in Digital Archives. Circulation. Pedagogy. Performance,' in Maaike Bleeker (ed.) Transmission in Motion: The Technologizing of Dance. London and New York, NY: Routledge, 155-167. 
boyd, danah and Kate Crawford (2012) 'Critical Questions for Big Data,' Information, Communication \& Society 15.5: 662-679.

Brynskov, Martin, Peter Dalsgaard and Kim Halskov (2015) 'Media Architecture: Engaging Urban Experiences in Public Space,' in Julia Lossau and Quentin Stevens (eds.) The Uses of Art in Public Space. New York, NY and London: Routledge, 51-66.

Chamberlain, Daniel (2011) 'Scripted Spaces: Television Interfaces and the NonPlaces of Asynchronous Entertainment,' in James Bennett and Niki Strange (eds.) Television as Digital Media. Durham, NC: Duke University, 203-254.

Cukier, Kenneth, and Viktor Mayer-Schoenberger (2013) 'Rise of Big Data: How it's Changing the Way We Think about the World,' The Foreign Affair 92, 28, https://www.foreignaffairs.com/articles/2013-04-03/rise-big-data. Accessed 17 September 2018.

Es, Karin van, and Mirko Tobias Schäfer (2017) 'Introduction: A Brave New World,' in Karin van Es and Mirko Tobias Schäfer (eds.) Datafied Society: Studying Culture through Data. Amsterdam: Amsterdam University Press, 14-22.

Featherstone, Mike (2006) 'Archive,' Theory, Culture \& Society 23: 591-596.

Grugier, Maxence (2016) 'The Digital Age of Data Art,' TechCrunch. 8 May 2016, https://techcrunch.com/2016/05/o8/the-digital-age-of-data-art/. Accessed 17 September 2018.

Haraway, Donna (1988) 'Situated Knowledges: The Science Question in Feminism and the Privilege of Partial Perspective,' Feminist Studies 14.3: 575-599.

Hookway, Branden (2014) Interface. Cambridge, MA: The MIT Press.

Johnson, Steve (1997) Interface Culture. New York, NY: Touchstone.

Kim, Tanyoung, and Carl DiSalvo (2010) 'Speculative Visualization: A New Rhetoric for Communicating Public Concerns,' DRS '10: Proceedings of the 2010 Design Research Society Conference, 1-10.

Kitchin, Rob (2014) The Data Revolution: Big Data, Open Data, Data Infrastructures and Their Consequences. London: Sage.

Mann, Steve, Jason Nolan and Barry Wellman (2003) 'Sousveillance: Inventing and Using Wearable Computing Devices for Data Collection in Surveillance Environments,' Surveillance \& Society 1.3: 331-355.

Manovich, Lev (2002) 'Data Visualization as New Abstraction and Anti-Sublime,' http://manovich.net/content/o4-projects/o4o-data-visualisation-as-newabstraction-and-anti-sublime/37_article_2002.pdf. Accessed 17 September 2018.

Mattern, Shannon (2015) 'Mission Control: A History of the Urban Dashboard,' Places Journal, https://placesjournal.org/article/mission-control-a-history-ofthe-urban-dashboard. Accessed 17 September 2018.

McQuire, Scott (2008) The Media City: Media, Architecture and Urban Space. London: Sage. 
Mollerup, Per (2013) Wayshowing $>$ Wayfinding: Basic \& Interactive. Amsterdam: BIS Publishers.

Presner, Todd, David Shepard and Yoh Kawano (2014) HyperCities: ThickMapping in the Digital Humanities. Cambridge, MA: Harvard University Press.

Rao, Vyjayanthi (2009) 'Embracing Urbanism: The City as Archive,' New Literary History 40.2: 371-383.

Roberts, Les (2015) 'Navigating the "Archive City": Digital Spatial Humanities and Archival Film Practice,' Convergence: The International Journal of Research into New Media Technologies 21.1: 100-115.

Struppek, Mirjam (2011) 'Urban Screens as the Visualization Zone of the City's Invisible Communication Sphere,' in Martin Rieser (ed.) The Mobile Audience: Media Art and Mobile Technologies. Amsterdam: Rodopi, 155-162.

Turkle, Sherry (ed.) (2007) Evocative Objects: Things We Think With. Cambridge, MA: The MIT Press.

Vande Moere, Andrew, and Dan Hill (2012) 'Designing for the Situated and Public Visualization of Urban Data,' Journal of Urban Technology 19.2: 25-46.

Verhoeff, Nanna (2012) Mobile Screens: The Visual Regime of Navigation. Amsterdam: Amsterdam University Press.

Verhoeff, Nanna (2013) 'The Medium is the Method: Locative Media for Digital Archives,' in Julia Eckel et al. (eds.) (Dis)Orienting Media and Narrative Mazes. Bielefeld, Germany: Transcript Verlag, 17-30.

Verhoeff, Nanna, and Clancy Wilmott (2016) 'Curating the City: Urban Interfaces and Locative Media as Experimental Platforms for Cultural Data,' in Rob Kitchin and Yeuh Perng (eds.) Code \& the City. London: Routledge, 116-129.

Verhoeff, Nanna, Heidi Rae Cooley and Heather Zwicker (2017) 'Urban Cartographies: Mapping Mobility and Presence,' Television \& New Media. 18.4: 298-304.

Weinberger, David (2011) Too Big to Know. New York, NY: Basic Books.

Whitelaw, Mitchell (2008) 'Art Against Information: Case Studies Against Data Practice,' Fibreculture Journal 11, http://eleven.fibreculturejournal.org/fcj-067-artagainst-information-case-studies-in-data-practice. Accessed 17 September 2018. Wiethoff, Alexander, and Heinrich Hussmann (2017) Media Architecture: Using Information and Media as Construction Material (Age of Access? Grundfragen der Informationsgesellschaft). Berlin: De Gruyter Mouton.

\section{About the authors}

Nanna Verhoeff is Associate Professor at the Department of Media and Culture Studies at Utrecht University, the Netherlands. Interested in comparative approaches for changing screen cultures, she publishes on emerging 
and transforming media from early cinema to contemporary mobile media, augmented reality, screen-based installations and media architecture. Her books include The West in Early Cinema:After the Beginning (2006) and Mobile Screens: The Visual Regime of Navigation (2012); she is also coeditor of a special issue on Urban Cartographies for Television and New Media (2017). In 2014, she initiated the interdisciplinary research group [urban interfaces] at Utrecht University - a platform for research on location-based and mobile media, art and performance in urban public spaces.

Karin van Es is Assistant Professor of Television and New Media at Utrecht University. Her current research focuses on how new forms of knowledge production through data affects public service broadcasting. Her past publications in outlets such as Television \& New Media, M/C Journal and First Monday have explored social TV and online deliberation. She recently coedited the volume The Datafied Society: Studying Culture through Data (AUP, 2017), which thinks through the opportunities and pitfalls of doing research with data within the humanities. 
A Amsterdam

U University

P Press 